\title{
Penectomia parcial em equino com carcinoma de células escamosas
}

Camilla Soares Scattaregi", Tatiana Harumi Saito, Bruno Marcondes de Oliveira, Gustavo Krauss Lemos, Tatiane Sandy Souza, Diogo SG Cruz, Thiago Pires Anacleto, Ana Carolina Ortegal Almeida, Everton Schimidt Prado, Sergio da Silva Rocha Júnior

Universidade José do Rosário Vellano (UNIFENAS), Alfenas, MG, Brasil

*Autor correspondente

e-mail: camilla.scattaregi@gmail.com

\section{Resumo}

O carcinoma de células escamosas (CCE) é uma neoplasia cutânea maligna e metastática dos queratinócitos, com prevalência em regiões onde há menor pigmentação da pele e pouca cobertura por pêlos, como pálpebras, prepúcio, vulva e junções mucocutâneas. A exposição prolongada à luz ultravioleta (UV), a ação cancerígena do esmegma, nos animais que não são higienizados periodicamente, e a correlação do papilomavírus equino tipo 2 estão entre as principais causas do desenvolvimento desta neoplasia. Várias terapias são descritas para o tratamento, sendo as mais eficazes a excisão cirúrgica, criocirurgia, hipertermia por rádio fluorescência, cirurgia a laser, radioterapia, quimioterapia, imunoterapia e combinação de todos estes métodos. Foi atendido no Hospital Veterinário de Grandes Animais, UNIFENAS, um equino, macho, com aproximadamente 12 anos de idade, escore corporal 3, pesando $350 \mathrm{KG}$ e pelagem tordilha. Durante o exame físico, constatou-se a presença de uma massa pedunculada de superfície irregular, de consistência firme, com áreas multifocais ulceradas envolvendo toda a glande do pênis. De acordo com a histórico do animal e os achados macroscópicos, suspeitou-se de um carcinoma de células escamosas. Desta forma, foi solicitada a remoção radical do tecido, e a técnica empregada foi a penectomia parcial. Uma vez removido, o material foi encaminhado para avaliação histológica, onde os achados foram condizentes com a suspeita de CCE. Não houveram complicações pós-operatórias e, até o último contato com o proprietário, o animal passa bem e retornou as suas atividades. Por se tratar de um equino macho de idade avançada, suspeita-se que a neoplasia foi ocasionada pela ação dos raios UV associada à presença constante de esmegma, uma vez que o proprietário não possuía o hábito de higienizar as genitálias do animal.

Palavras-chave: Equino. Neoplasia. Penectomia. 